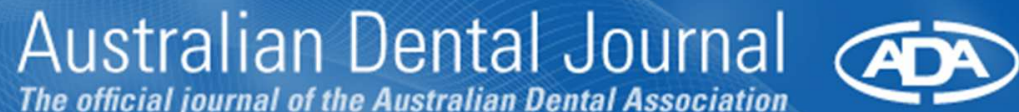

\section{Ion release from calcium and fluoride containing dental varnishes}

\begin{tabular}{|r|l|}
\hline Journal: & Australian Dental Journal \\
\hline Manuscript ID: & ADJ-04-13-0263.R1 \\
\hline Manuscript Type: & Original Article \\
\hline Keywords: & ACP, CPP-ACP, calcium phosphate, calcium fluoride, fluoride varnish \\
\hline \multicolumn{2}{|c}{} \\
\hline
\end{tabular}

\section{SCHOLARONE \\ Manuscripts}


1

2

3

4

5

6

7

8

9

10

11

12

13

14

15

16

17

18

19

20

21

22

23

24

25

26

27

28

29

30

31

32

33

34

35

36

37

38

39

40

41

42

43

44

45

46

47

48

49

50

51

52

53

54

55

56

57

58

59

60

\section{Ion release from calcium and fluoride containing dental varnishes}




\begin{abstract}
ASTRACT
Background: A range of dental varnishes have been commercialized recently that contain calcium and inorganic phosphate in addition to fluoride. The aim of this study was to analyze the fluoride, calcium and inorganic phosphate ion release from: 1) MI Varnish containing casein phosphopeptide amorphous calcium phosphate (CPP-ACP); 2) Clinpro White containing functionalized tricalcium phosphate (fTCP); 3) Enamel Pro containing amorphous calcium phosphate; 4) Bifluorid 5 containing calcium fluoride; and 5) Duraphat (no added calcium control).
\end{abstract}

Method: The varnishes were applied to a standardized surface area of polyvinyl chloride $(\mathrm{n}=7$ per group) and immersed in $25 \mathrm{~g}$ of distilled deionized water which was changed at 1, 4, 24, 72 and 168 hours. The ion release was determined by ion chromatography and expressed as $\mu \mathrm{mol}$ (cumulative) per $\mathrm{g}$ of varnish.

Results: All varnishes released measurable fluoride and calcium, however only MI Varnish and Enamel Pro released significant levels of inorganic phosphate. At 24 hours the order of cumulative fluoride release was: $1>3>4>2=5$ with 1 significantly higher $(\mathrm{p}<0.05)$ than the rest. At 72 and 168 hours the cumulative calcium release was: $1>4>3>2=5$ with 1 significantly higher $(p<0.05)$ than the rest.

Conclusions: MI Varnish containing CPP-ACP had the highest release of calcium and fluoride ions.

Key words: ACP; CPP-ACP; calcium phosphate; calcium fluoride; fluoride varnish 


\section{INTRODUCTION}

Recently a range of calcium phosphate technologies have been developed to enhance the ability of fluoride to prevent demineralization and promote remineralization. ${ }^{1}$ These technologies can be divided into the following types: i) crystalline, such as functionalized tricalcium phosphate (fTCP), ${ }^{2}$ ii) glasses, such as calcium sodium phosphosilicates (NovaMin), ${ }^{3}$ (iii) unstabilized, such as the Amorphous Calcium Phosphate technology $(\mathrm{ACP})^{4}$ and (iv) stabilized, such as casein phosphopeptide amorphous calcium phosphate nanocomplexes (CPP-ACP). ${ }^{5}$ Many of these technologies have been incorporated into crèmes, dentifrices, bleaching agents, restorative materials and more recently into fluoride varnishes.

The integrity of the dental hard tissues relies on the oral fluids being saturated or supersaturated with respect to tooth mineral. Therefore, having sufficient levels of bioavailable calcium, phosphate and hydroxide or fluoride ions in the oral fluid bathing the teeth is essential. Fluoride varnishes were developed in the 1960 's to provide an additional intra-oral reservoir of fluoride ions. ${ }^{6}$ Since then, substantial clinical testing has validated their caries preventive efficacy with a meta-analysis concluding that the $\mathrm{D}(\mathrm{M}) \mathrm{FS}$ pooled preventive fraction estimate was $46 \% .{ }^{7}$ Fluoride varnishes are proposed to promote the formation of intra-oral fluoride reservoirs due to the formation of calcium fluoride $\left(\mathrm{CaF}_{2}\right)$, "calcium fluoride-like" or biologically/bacterially bound calcium fluoride $\left(\mathrm{CaF}^{+}\right) .{ }^{8}$ As such, the formation of these reservoirs is limited by calcium ion and fluoride ion availability. ${ }^{8}$ Therefore, there is a sound rationale for the addition of calcium ions to fluoride containing varnishes in an attempt to produce an increased retention of fluoride and calcium ions in the oral environment. Additionally, the remineralization potential of saliva is also calcium limited $^{1,9}$ so additional calcium and phosphate ions from sources such as varnish may lead to improved remineralization of early lesions. Hence, a number of manufacturers have modified 
fluoride varnishes to include calcium and inorganic phosphate ions in an attempt to further improve efficacy.

Fluoride containing varnishes are now available containing fTCP consisting of tricalcium phosphate modified by fumaric acid (Clinpro White), ACP (Enamel Pro), $\mathrm{CaF}_{2}$ (Bifluorid 5) and CPP-ACP (MI Varnish). Whereas the fluoride release from fluoride varnishes has been studied in detail ${ }^{10,11}$ no studies have examined ion release from these new calcium and fluoride containing varnishes. This is particularly important given that fluoride in the presence of calcium and inorganic phosphate can react to form relatively poorly soluble phases and thereby reduce bioavailability. ${ }^{12}$ Hence, the aim of this study was to determine the fluoride, calcium and inorganic phosphate ion release from a variety of calcium and fluoride containing varnishes. The null hypothesis was that there would be no significant differences in ion release from the different varnishes.

\section{MATERIALS AND METHODS}

\section{Varnish selection}

Five dental varnishes were selected for analysis (Table 1): 1. MI Varnish containing CPPACP with 2.26\% (w/w) fluoride; 2. Clinpro White with fTCP containing $2.26 \%(\mathrm{w} / \mathrm{w})$ fluoride; 3. Enamel Pro containing ACP and 2.26\% (w/w) fluoride; 4. Bifluorid 5 containing $0.3 \%(\mathrm{w} / \mathrm{w})$ calcium fluoride and $0.3 \%(\mathrm{w} / \mathrm{w})$ sodium fluoride; and 5. Duraphat containing $2.26 \%(\mathrm{w} / \mathrm{w})$ fluoride (positive control).

\section{Ion release}

Seven polyvinyl chloride plastic strips (Clear Binding Covers; Cumberland, NSW, Australia), $40 \mathrm{~mm}$ long by $20 \mathrm{~mm}$ wide, were completely coated with a single layer of one of the different varnishes. The amount of varnish painted on each strip was determined by weighing 
the strip before and after applying the varnish. The weight of each of the varnishes that covered the standardized area of the plastic strip ( $\mathrm{n}=7)$ was: MI Varnish $194.5 \pm 0.3 \mathrm{mg}$; Clinpro White 233.5 土 0.6 mg; Enamel Pro 218.0 $\pm 1.0 \mathrm{mg}$; Bifluorid $565.3 \pm 1.4 \mathrm{mg}$; and Duraphat $163.7 \pm 1.1 \mathrm{mg}$. The painted strips were placed into $25 \mathrm{ml}$ of distilled deionized water and stored in an incubator at $37^{\circ} \mathrm{C}$. At each of the following time points: 1, 4, 24, 72, and 168 hours each strip was removed from the water and placed in a new container with 25 $\mathrm{ml}$ of fresh water. The samples were analysed using ion chromatography to determine the release of calcium, inorganic phosphate and fluoride ions. The ion chromatography system was equipped with cation (IonPac CS12; Dionex, CA, USA) and anion (IonPac AS18; Dionex, CA, USA) columns and two separated conductivity detectors (ICS-3000; Dionex, CA, USA). A combined seven anion standard (\#56933; Dionex, CA, USA) and a combined six cation standard (\#046070; Dionex, CA, USA) were diluted with distilled deionized water to produce a range of concentrations to calibrate and quantify the conductivity readings. Prior to commencing the study the polyvinyl strips were tested to ensure that they did not release any of the ions of interest. The cumulative release of calcium, inorganic phosphate and fluoride ions was expressed as $\mu \mathrm{mol}$ per gram of varnish applied to the strips at each of the time points.

\section{Photography}

Digital images of varnish samples were taken at baseline, 24 hours and 168 hours of exposure to the water. Images were captured using a digital camera (Model D2X; Nikon, Tokyo, Japan) fitted with a macro lens (Lens AF Micro NIKKOR 105 mm; Nikon, Tokyo, Japan) under standardised lighting conditions (Prolinca 2500 flash head; ELINCHROM, Geneva, Switzerland). 


\section{Data analysis}

Data sets were analysed for normality and equality of variance and means compared using a one-way ANOVA with Dunnett T3 post hoc using SPSS version 17.0 software (SPSS, Chicago, IL, USA). For all statistical tests, the significance level was set at $\alpha=0.05$.

\section{RESULTS}

\section{Calcium ion release}

The cumulative calcium ion release from the varnishes expressed as $\mu \mathrm{mol}$ per $\mathrm{g}$ of varnish is shown in Table 2. All varnishes were found to release detectable calcium. MI Varnish had the highest release $(\mathrm{p}<0.05)$ of calcium at 4,72 and 168 hours. After 168 hours the greatest to least cumulative release of calcium was MI Varnish $>$ Bifluorid $5>$ Enamel Pro $>$ Clinpro White $>$ Duraphat. Over all time points, except 168 hours, Clinpro White had a similar calcium release compared with Duraphat.

\section{Inorganic phosphate ion release}

The cumulative inorganic phosphate ion release expressed as $\mu$ mol per $g$ of varnish is shown in Table 3. Only MI Varnish and Enamel Pro varnish were found to release detectable levels of inorganic phosphate ions at all time points. Enamel Pro released the greatest amount of inorganic phosphate at all time points and this release was rapid with the majority released within 24 hours. MI Varnish had a more prolonged inorganic phosphate ion release profile. Clinpro White released low levels of inorganic phosphate that were only detectable after 24 hours of exposure. Bifluorid 5 and Duraphat did not release detectable levels of inorganic phosphate.

\section{Fluoride ion release}


The cumulative fluoride ion release expressed as $\mu$ mol per $\mathrm{g}$ of varnish is shown in Table 4. MI Varnish and Bifluorid 5 released approximately all of their added fluoride based on the manufacturer's specification within 24 hours. Enamel Pro released approximately $60 \%$ of its added fluoride in the first 24 hours after which its rate of release slowed. Clinpro White and Duraphat released less than one third of their added fluoride after immersion in water for 168 hours. The fluoride release from MI varnish was significantly higher $(\mathrm{p}<0.05)$ at 4, 24, 72 and 168 hour time points when compared with that from all the other varnishes tested (Table 4).

\section{Photography}

Images of the varnishes at baseline, 24 hours and 168 hours are shown in Figure 1. The varnishes behaved differently after exposure to water with the Clinpro White appearing unstable with the varnish bubbling. Bifluorid 5 became more visible after water exposure. Duraphat became less orange whereas the Enamel Pro and MI Varnish did not appreciably change in appearance.

\section{DISCUSSION}

Fluoride varnish has a short life span in the oral environment as it is removed by the action of the cheeks and tongue, salivary flow, mastication and oral hygiene procedures. Therefore, varnishes should release their ions in a relatively short time period before the varnish is lost.

It has been estimated that varnishes only remain in situ for up to 24 hours. ${ }^{13}$ Therefore, in this in vitro study three of the five release time points examined were in the first 24 hours.

Differences were found in the ion release of calcium, inorganic phosphate and fluoride ions from the different varnishes therefore the null hypothesis was rejected.

Duraphat was chosen as the positive control in this study as it is a commonly used 
fluoride varnish that has been tested by other authors in similar experiments. ${ }^{10,11}$ Shen and Autio-Gold ${ }^{11}$ examined the in vitro fluoride ion release of Duraphat into artificial saliva. After 7 days exposure they found Duraphat released approximately $30 \%$ of its total fluoride which was similar to the $33 \%$ release into distilled deionized water found in this study after the same exposure period. Distilled deionized water will be undersaturated with respect to all solid calcium phosphate fluoride phases so ion release from the varnish in this environment may occur more readily than in saliva.

Considering the fluoride ion release of the varnishes first, it is important that the addition of calcium and phosphate ions do not reduce the availability of fluoride ions as it is the fluoride that has been shown in clinical trials to provide the caries preventive efficacy of the varnish. ${ }^{7}$ All calcium-containing varnishes were found to have a cumulative release of fluoride ions at 24 hours that was similar or better than that of the positive control Duraphat. However, Clinpro White released less fluoride than Duraphat at 1 and 4 hours and the 168 hour cumulative fluoride release of Bifluorid 5 and Clinpro White were both significantly below that of Duraphat. The information on the packaging indicated that MI Varnish, Clinpro White, Enamel Pro and Duraphat all contained $2.26 \mathrm{wt} \%$ fluoride whereas Bifluorid 5 contained $0.28 \mathrm{wt} \%$. Therefore, after 24 hours the percentage fluoride release from Bifluorid 5, MI Varnish, Enamel Pro, Clinpro White and Duraphat was 97\%, 96\%, 58\%, 6\% and 6\% respectively. After 168 hours the cumulative fluoride release from the varnishes was Bifluorid 5, MI Varnish, Enamel Pro, Duraphat and Clinpro White with 163\%, 103\%, 65\%, $33 \%$ and $20 \%$ respectively. The higher than total fluoride release from Bifluorid 5 is likely to be explained by the difficulty experienced in weighing the varnish after application to the strips. The Bifluorid 5 varnish had a high content of volatile ingredients (Table 1) that would have resulted in an underestimation of the weight of varnish applied and hence an overestimation of ion release per $\mathrm{g}$ of varnish. Overall, the MI Varnish and the Enamel Pro 
varnish performed best in terms fluoride ion release over all time points.

Calcium ions were released from all varnishes tested whereas inorganic phosphate ions were only released from three varnishes (MI Varnish, Enamel Pro and Clinpro White). The greatest cumulative calcium release at all time points was from MI Varnish, although this was only statistically significant at 4, 72 and 168 hours. The Bifluorid 5 cumulative calcium release was again over the theoretical total $(38.4 \mu \mathrm{mol} / \mathrm{g})$ which again would be related to the underestimation of the amount of varnish applied. Enamel Pro also had a notable release of calcium ions. Clinpro White had comparable calcium ion release to Duraphat at all time points except at 168 hours where it was marginally higher. Presumably one of the ingredients in Duraphat contains some calcium ions which are released on exposure to water. Calcium ions are of critical importance in the oral environment as levels in the plaque fluid become depleted by regular sucrose exposure ${ }^{14}$ and are required for the promotion of remineralization. ${ }^{1}$

At all time points the inorganic phosphate ion release from greatest to least was Enamel Pro $>$ MI Varnish $>$ Clinpro White. The release of inorganic phosphate ions in the oral environment may be the least important of the three ions given the relatively high availability of inorganic phosphate in the oral environment $(8-10 \mathrm{mM}$ phosphate $>1-2 \mathrm{mM}$ calcium $>1-10 \mu \mathrm{M}$ fluoride). ${ }^{14}$ High inorganic phosphate levels may also be problematic for the formation of loosely bound fluoride reservoirs as they can inhibit the formation of $\mathrm{CaF}^{+}$ and $\mathrm{CaF}_{2}$ and favour the formation of fluorapatite. ${ }^{15}$ The formation of fluorapatite ectopically will effectively decrease the fluoride ion activity and may promote calculus formation. Therefore, the high inorganic phosphate release from Enamel Pro varnish may be counter productive in terms of localising bioavailable fluoride ions in the oral environment.

Recently a study by Schemehorn et al. ${ }^{13}$ examined the fluoride uptake into or onto sound and demineralized bovine enamel that had been treated with an ACP (Enamel Pro) and 
fTCP containing dental varnish (Omni Vanish White). The varnishes were applied to the sound enamel core adjacent to a demineralized core and then both were exposed to artificial saliva for 24 hours. It was found that the ACP varnish promoted significantly more fluoride deposition into or onto sound and demineralized enamel than the fTCP containing varnish.

The authors postulated that this was due to the ACP varnish containing a higher level of available calcium and phosphate ions. ${ }^{13}$ The 24 hour ion release data from the current study are consistent with this explanation as the ACP containing varnish had significantly higher 24 hour release of calcium, inorganic phosphate and fluoride ions than the fTCP containing varnish. However, it is not known whether the ACP containing varnish deposited this strongly bound fluoride onto the surface or within the enamel and as discussed earlier strongly bound fluoride as ectopic fluorapatite may be of limited value in influencing the dynamics of the dental caries process. The authors of that study did not measure the loosely bound fluoride released by the ACP containing varnish. The low release of calcium and inorganic phosphate ions from Clinpro White may be explained by a low amount of fTCP being added to the varnish or by the very low solubility of tricalcium phosphate.

Overall the MI Varnish had good release of calcium and inorganic phosphate ions which is consistent with the bioavailable nature of CPP-ACP contained within the varnish. ${ }^{16}$ The fast release of the ions from MI Varnish under the relatively neutral conditions studied may be attributed to the high water solubility of the CPP-ACP complexes. ${ }^{16}$ Enamel Pro had a high release of inorganic phosphate ions and lower release of calcium ions which is consistent with the order of ingredients listed on the material safety data sheet (Table 1). The Bifluorid 5 appeared to have good release of its calcium ions but the accuracy of these results need to be kept in mind given the technical difficulties in working with this varnish. Clinpro White had low levels of calcium and inorganic phosphate ion release. The combined use of calcium and fluoride, in particular CPP-ACP and fluoride has been shown to increase the 
level of calcium and fluoride ions in plaque ${ }^{17,18}$ so these novel varnishes may have potential to further improve caries prevention.

\section{CONCLUSION}

The ion release profile of MI Varnish was the most promising as it had high fluoride and calcium ion release. All calcium-containing varnishes except for Clinpro White containing fTCP released substantially more calcium than the positive control. 


\section{REFERENCES}

1. Cochrane NJ, Cai F, Huq NL, Burrow MF, Reynolds EC. New approaches to enhanced remineralization of tooth enamel. J Dent Res 2010;89:1187-1197.

2. Karlinsey RL, Mackey AC. Solid-state preparation and dental application of an organically modified calcium phosphate. J Mat Sci 2009;44:346-349.

3. Cao W, Hench LL. Bioactive materials. Ceramics International 1996;22:493-507.

4. Tung MS, Eichmiller FC. Amorphous calcium phosphates for tooth mineralization. Compend Contin Educ Dent 2004;25:9-13.

5. Reynolds EC. Remineralization of enamel subsurface lesions by casein phosphopeptide-stabilized calcium phosphate solutions. J Dent Res 1997;76:15871595.

6. Schmidt HF. The fluoride varnish procedure and possibilities of its utilization for the prevention of caries. Zahnarztl Mitt 1969;59:633-636.

7. Marinho VC, Higgins JP, Logan S, Sheiham A. Fluoride varnishes for preventing dental caries in children and adolescents. Cochrane database of systematic reviews (Online) 2002CD002279.

8. Vogel GL. Oral fluoride reservoirs and the prevention of dental caries. In: Buzalaf MAR, ed. Fluoride and the oral environment. Basel: Monographs in Oral Science, Karger, 2011:146-157.

9. $\quad$ ten Cate JM. In situ models, physico-chemical aspects. Advan Dent Res 1994;8:125133.

10. Castillo JL, Milgrom P, Kharasch E, Izutsu K, Fey M. Evaluation of fluoride release from commercially available fluoride varnishes. J Am Dent Assoc 2001;132:13891392.

11. Shen C, Autio-Gold J. Assessing fluoride concentration uniformity and fluoride 
release from three varnishes. J Am Dent Assoc 2002;133:176-182.

12. Pfarrer AM, Karlinsey RL. Challenges of implementing new remineralization technologies. Advan Dent Res 2009;21:79-82.

13. Schemehorn BR, Wood GD, McHale W, Winston AE. Comparison of fluoride uptake into tooth enamel from two fluoride varnishes containing different calcium phosphate sources. J Clin Dent 2011;22:51-54.

14. Tenuta LM, Del Bel Cury AA, Bortolin MC, Vogel GL, Cury JA. Ca, Pi, and F in the fluid of biofilm formed under sucrose. J Dent Res 2006;85:834-838.

15. Christoffersen J, Christoffersen MR, Kibalczyc W, Perdok WG. Kinetics of dissolution and growth of calcium fluoride and effects of phosphate. Acta odontologica Scandinavica 1988;46:325-336.

16. Cochrane NJ, Reynolds EC. Casein phosphopeptides in oral health. In: Wilson M, ed. Food constituents and oral health: current status and future prospects. Cambridge: Woodhead Publishing Limited, 2009.

17. Reynolds EC, Cai F, Cochrane NJ, et al. Fluoride and casein phosphopeptideamorphous calcium phosphate. J Dent Res 2008;87:344-348.

18. Vogel GL, Schumacher GE, Chow LC, Takagi S, Carey CM. Ca pre-rinse greatly increases plaque and plaque fluid F. J Dent Res 2008;87:466-469. 


\section{FIGURE LEGEND}

Figure 1: Appearance of the varnishes at baseline and after 24 and 168 hours of immersion in water. 
Table 1. Fluoride varnishes selected for analysis

\begin{tabular}{|c|c|c|c|c|c|}
\hline Product & Manufacturer & Batch No. & $\begin{array}{l}\text { Expiry } \\
\text { Date }\end{array}$ & Composition (w/w) & Source \\
\hline MI Varnish & GC, Tokyo, Japan & 1107011 & $07-2014$ & $\begin{array}{l}30-50 \% \text { polyvinyl acetate, } 10-30 \% \text { hydrogenated } \\
\text { rosin, } 20-30 \% \text { ethanol, } 1-8 \% \text { sodium fluoride, } 1-5 \% \\
\text { CPP-ACP, } 1-5 \% \text { silicon dioxide }\end{array}$ & MSDS \\
\hline $\begin{array}{l}\text { Clinpro } \\
\text { White }\end{array}$ & 3M ESPE, MN, USA & M14380H1E & $10-2012$ & $\begin{array}{l}30-75 \% \text { pentaerythritol glycerol ester of colophony } \\
\text { resin, } 10-15 \% \text { n-hexane, } 1-15 \% \text { ethyl alcohol, } 1-5 \% \\
\text { sodium fluoride, } 1-5 \% \text { flavour enhancer, } 1-5 \% \\
\text { thickener, } 1-5 \% \text { food grade flavour, }<5 \% \text { modified } \\
\text { tricalcium phosphate }\end{array}$ & MSDS \\
\hline Enamel Pro & $\begin{array}{l}\text { Premier Dental } \\
\text { Products, PA, USA }\end{array}$ & 34220 & $05-2012$ & $\begin{array}{l}\text { rosin, ethanol, } 5 \% \text { sodium fluoride, dibasic sodium } \\
\text { phosphate, calcium sulfate dihydrate }\end{array}$ & MSDS \\
\hline Bifluorid 5 & $\begin{array}{l}\text { Voco, Cuxhaven, } \\
\text { Germany }\end{array}$ & 1112147 & $02-2014$ & $\begin{array}{l}65-70 \% \text { ethyl acetate, } 0.3 \% \text { sodium fluoride, } 0.3 \% \\
\text { calcium fluoride }\end{array}$ & $\begin{array}{l}\text { MSDS and } \\
\text { Manufacturer }\end{array}$ \\
\hline Duraphat & $\begin{array}{l}\text { Colgate Oral Care, } \\
\text { NSW, Australia }\end{array}$ & 902991 & 04-2012 & $\begin{array}{l}30-60 \% \text { colophonium, } 10-30 \% \text { ethanol, } 5 \% \text { sodium } \\
\text { fluoride, other ingredients }\end{array}$ & MSDS \\
\hline
\end{tabular}

MSDS $=$ material safety data sheet 
Table 2. Cumulative calcium ion release $(\mu \mathrm{mol} / \mathrm{g})$ from the varnishes (mean (SD))

\begin{tabular}{llllll}
\hline & 1 hour & 4 hours & 24 hours & 72 hours & 168 hours \\
\hline MI Varnish & $2.9(1.4)^{\mathrm{a}}$ & $8.5(2.1)$ & $18.2(2.1)^{\mathrm{a}}$ & $46.5(1.9)$ & $73.5(2.7)$ \\
Clinpro White & $0.8(0.6)^{\mathrm{a}}$ & $1.7(0.6)^{\mathrm{a}}$ & $3.2(0.9)^{\mathrm{b}}$ & $4.0(1.0)^{\mathrm{a}}$ & $4.5(1.1)$ \\
Enamel Pro & $1.4(0.6)^{\mathrm{a}}$ & $2.9(0.9)^{\mathrm{a}, \mathrm{b}}$ & $16.4(1.5)^{\mathrm{a}}$ & $23.7(1.8)$ & $34.7(2.0)$ \\
Bifluorid 5 & $2.7(1.6)^{\mathrm{a}}$ & $4.0(1.3)^{\mathrm{b}}$ & $10.5(2.5)$ & $33.3(4.1)$ & $57.7(5.0)$ \\
Duraphat & $1.7(0.6)^{\mathrm{a}}$ & $2.1(0.6)^{\mathrm{a}, \mathrm{b}}$ & $2.5(0.7)^{\mathrm{b}}$ & $2.7(0.7)^{\mathrm{a}}$ & $2.9(0.7)$ \\
\hline
\end{tabular}

Similarly marked in same column are not significantly different ( $\mathrm{p}>0.05$, ANOVA with Dunnett T3 post hoc) 
Table 3. Cumulative inorganic phosphate ion release $(\mu \mathrm{mol} / \mathrm{g})$ from the varnishes (mean (SD))

\begin{tabular}{lccccc}
\hline & $\mathbf{1}$ hour & $\mathbf{4}$ hours & $\mathbf{2 4}$ hours & $\mathbf{7 2}$ hours & $\mathbf{1 6 8}$ hours \\
\hline MI Varnish & $7.2(1.5)$ & $24.7(2.7)$ & $31.5(3.2)$ & $34.9(3.4)$ & $36.7(4.2)$ \\
Clinpro White & nd & nd & $0.8(0.3)$ & $1.5(0.5)$ & $2.2(0.7)$ \\
Enamel Pro & $157.2(13.0)$ & $197.0(9.1)$ & $199.2(9.2)$ & $201.3(9.1)$ & $203.3(9.2)$ \\
Bifluorid 5 & nd & nd & nd & nd & nd \\
Duraphat & nd & nd & nd & nd \\
\hline
\end{tabular}

nd $=$ not detected

Values in each column are significantly different ( $\mathrm{p}<0.05$, ANOVA with Dunnett T3 post hoc) 
Table 4. Cumulative fluoride ion release $(\mu \mathrm{mol} / \mathrm{g})$ from the varnishes (mean (SD)).

\begin{tabular}{lccccc}
\hline & 1 hour & 4 hours & 24 hours & 72 hours & 168 hours \\
\hline MI Varnish & $276.5(39.2)$ & $889.5(79.6)$ & $1139.9(90.0)$ & $1192.8(93.5)$ & $1230.2(94.8)$ \\
Clinpro White & $5.8(0.8)$ & $11.9(2.1)$ & $74.0(34.2)^{\mathrm{a}}$ & $132.7(53.3)^{\mathrm{a}}$ & $234.9(64.9)^{\mathrm{a}}$ \\
Enamel Pro & $378.2(47.7)$ & $595.7(14.6)$ & $687.5(16.1)$ & $726.0(16.4)$ & $770.2(13.7)$ \\
Bifluorid 5 & $126.4(8.6)$ & $130.5(9.6)$ & $144.2(8.4)$ & $193.0(9.4)^{\mathrm{a}}$ & $241.4(16.1)^{\mathrm{a}}$ \\
Duraphat & $18.1(0.7)$ & $28.1(0.9)$ & $74.7(7.5)^{\mathrm{a}}$ & $236.6(27.2)^{\mathrm{a}}$ & $398.0(28.3)$ \\
\hline
\end{tabular}

Similarly marked in same column are not significantly different ( $\mathrm{p}>0.05$, ANOVA with Dunnett T3 post hoc) 


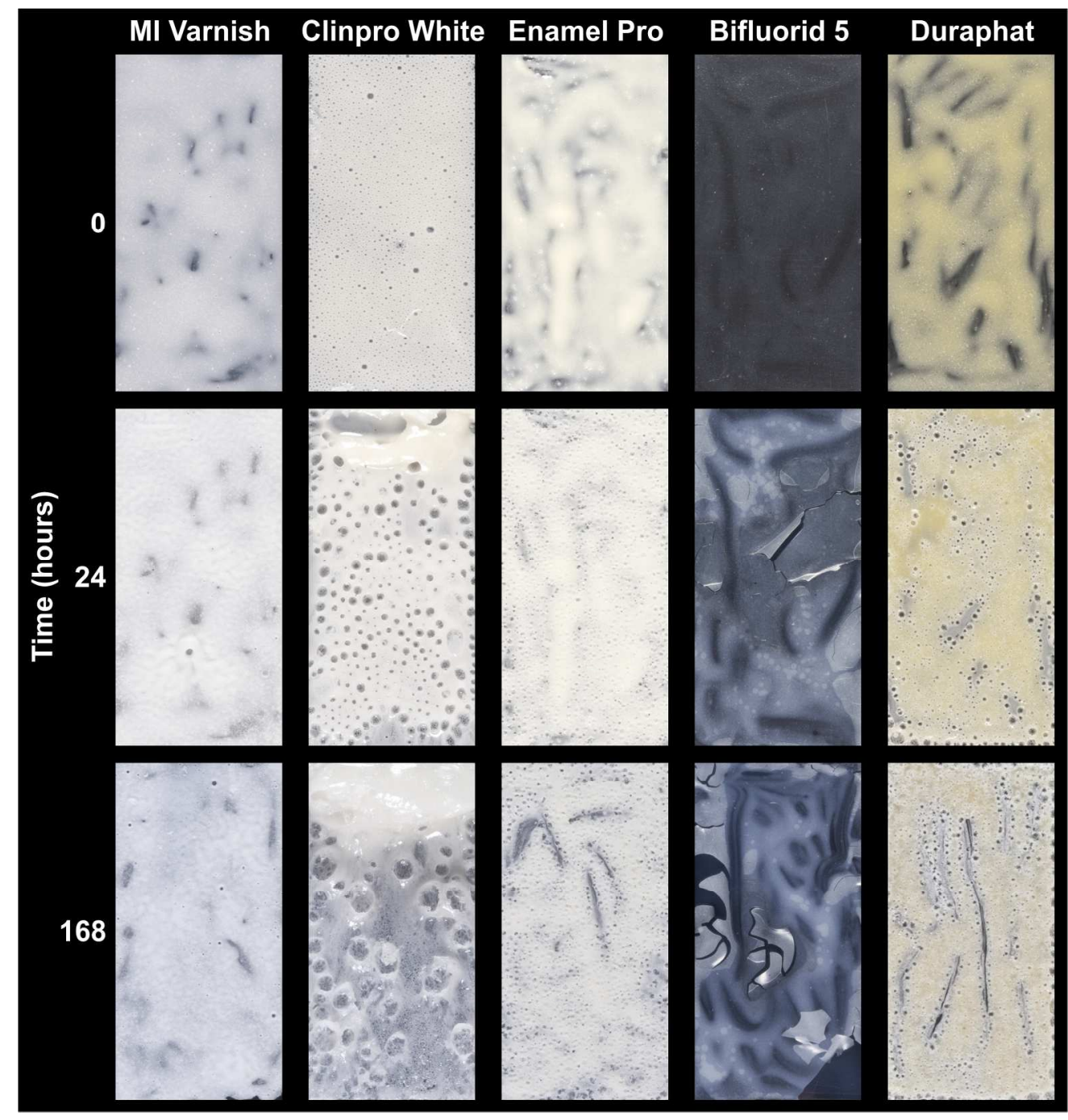

$183 \times 192 \mathrm{~mm}(300 \times 300 \mathrm{DPI})$ 


\section{University Library}

\section{- M M I N E R VA A gateway to Melbourne's research publications}

Minerva Access is the Institutional Repository of The University of Melbourne

Author/s:

Cochrane, NJ;Shen, P;Yuan, Y;Reynolds, EC

Title:

Ion release from calcium and fluoride containing dental varnishes

Date:

2014-03-01

Citation:

Cochrane, N. J., Shen, P., Yuan, Y. \& Reynolds, E. C. (2014). Ion release from calcium and fluoride containing dental varnishes. AUSTRALIAN DENTAL JOURNAL, 59 (1), pp.100-105. https://doi.org/10.1111/adj.12144.

Persistent Link:

http://hdl.handle.net/11343/108592 